\title{
I IL-10 Gene Transfection in Primary Endothelial Cells via Linear and 2 Branched Poly $(\beta$-amino ester) Nanoparticles Attenuates Inflammation in Stimulated Macrophages
}

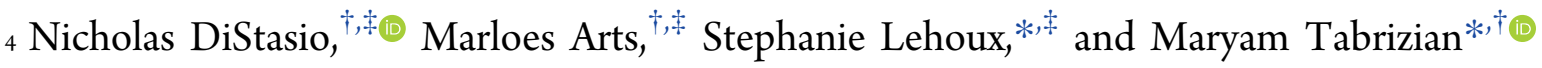 \\ $5{ }^{\dagger}$ Department of Biomedical Engineering, McGill University, 3773 University, Montréal, QC H3A 2B6, Canada \\ $6{ }^{\ddagger}$ Lady Davis Institute, Department of Medicine, McGill University, 3755 Chemin de la Côte-Sainte-Catherine, Montréal, QC H3T \\ 7 1E2, Canada
}

8 S Supporting Information
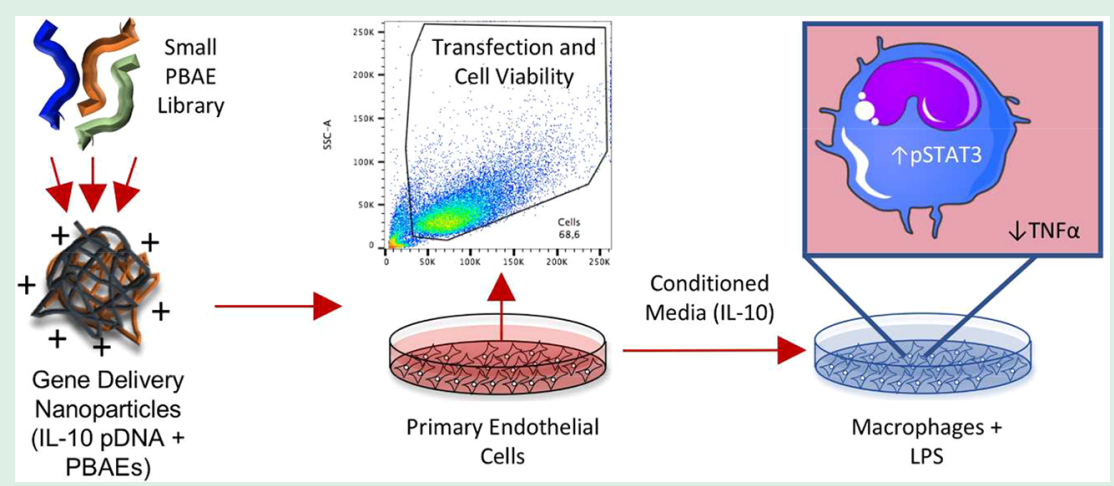

9 ABSTRACT: $\operatorname{Poly}(\beta$-amino esters $)$ or PBAEs are highly efficient synthetic polymers optimized for gene delivery, a complicated 10 process dependent on polymer properties such as hydrophobicity, charge, and degradability. The modular design of PBAEs has 11 allowed for the identification of which polymer and nanoparticle properties significantly affect gene delivery efficiency in various 12 cell types. However, these investigations need to be extended to more difficult-to-transfect cells such as primary endothelial 13 cells, which hold enormous potential for atherosclerosis. Here a small library of 6 different PBAEs were screened for efficacy and 14 safety in two types of primary endothelial cells (ECs). Nearly all polymers were more efficient than commercial transfection 15 reagents $(p<0.05)$, reaching $60 \%$ and $15 \%$ transfection efficiency in human and mouse primary ECs, respectively. The top 16 performing PBAE was used to deliver a plasmid encoding the anti-inflammatory cytokine interleukin-10 (IL-10), which has the 17 potential to reduce inflammation in atherosclerosis. Significant increases in IL-10 mRNA and protein were detectable in ECs 72 $18 \mathrm{~h}$ after transfection with PBAE:IL-10 nanoparticles. Macrophages cultured in conditioned medium from IL10-transfected ECs 19 showed activation of anti-inflammatory signaling pathways. In addition, these macrophages secreted significantly less (25\%) 20 tumor necrosis factor $\alpha(\mathrm{TNF} \alpha)$ when challenged with lipopolysaccharide (LPS). These results underline the capabilities of 21 PBAEs to be expanded as a fine-tunable platform for anti-inflammatory gene delivery within the context of atherosclerosis.

22 KEYWORDS: atherosclerosis, polymer nanoparticles, gene therapy, interleukin-10, endothelial cells, macrophages

\subsection{INTRODUCTION}

23 Poly $(\beta$-amino esters $)$ or PBAEs are biodegradable synthetic 24 polymers used for gene delivery due to their excellent 25 transfection abilities that have been illustrated in various cell 26 types. ${ }^{1}$ These cationic PBAEs condense anionic plasmid DNA 27 into polymer:DNA nanoparticles (NPs) or polyplexes via 28 electrostatic interactions and have been synthesized in 29 thousands of permutations. Electrostatic interactions are strong 30 enough to hold complexes together in physiological conditions, 31 but ester bonds within PBAEs degrade rapidly to release DNA 32 once inside the cell. Thus, the top-performing PBAEs exhibit a 33 delicate balance between hydrophobicity and cationic charge, ${ }^{2}$ 34 which are mainly influenced by the choice of end-capping 35 amine group. ${ }^{3,4}$ PBAEs with branched structures have also been reported to increase gene transfection, likely due to the 36 increased density of end-capping groups. ${ }^{5,6}$ However, the 37 majority of studies utilizing PBAEs have been performed in 38 relatively easy-to-transfect cell types, such as Chinese hamster 39 ovary (CHO), COS-7, and human embryonic kidney 40 (HEK293).

Relatively few studies have shown successful transfection 42 using linear PBAEs in the more difficult-to-transfect 43 endothelial cells (ECs) ${ }^{7-9}$ with no studies yet reported on 44 branched PBAEs in endothelial cells. The difficulty in 45

Received: July 19, 2018

Accepted: August 16, 2018

Published: August 16, 2018 
46 transfecting ECs arises mainly because of their confluent 47 resting state and low rate of division, which restricts access to 48 the nucleus. ${ }^{10}$ In addition, ECs secrete a negatively charged, 49 highly sulfated matrix-like film known as the glycocalyx that 50 further inhibits nanoparticle uptake. ${ }^{11}$ Despite these difficul51 ties, they remain a desirable target for gene delivery in 52 cardiovascular disease (CVD), the leading cause of mortality in 53 western society. ${ }^{12}$ Indeed, ECs have been targeted in previous 54 studies for imaging and the delivery of therapeutics for 55 atherosclerosis, the leading cause of clinical events in $56 \mathrm{CVD} .^{13-15}$ As ECs overlie the atherosclerotic plaque, they 57 secrete chemokines, cytokines, microRNAs, and growth factors 58 that influence monocyte recruitment and differentiation into 59 macrophages, which cultivate the chronic inflammation that 60 drives atherosclerosis. ${ }^{16}$

61 Atherosclerosis is characterized by the accumulation of lipid62 laden cells in a pro-inflammatory milieu where cytokines and 63 matrix-degrading enzymes create a complex plaque that is 64 prone to rupture. The formation and progression of 65 atherosclerotic plaques are driven in part by the nuclear 66 factor $-\kappa \mathrm{B}(\mathrm{NF}-\kappa \mathrm{B})$ signaling pathway, which is activated in 67 endothelial cells and macrophages among other cell types. ${ }^{17,18}$ 68 Many of the downstream products of NF- $\kappa \mathrm{B}$ signaling, such as 69 the prototypical pro-inflammatory cytokine $\mathrm{TNF} \alpha$, can be 70 offset by anti-inflammatory cytokines such as IL-10. ${ }^{19}$ In 71 mouse models, the overexpression or delivery of IL-10 has 72 been shown to attenuate the inflammation involved in 73 atherosclerosis, ${ }^{20-23}$ though nonviral delivery of IL-10 in 74 atherosclerosis has not yet been reported. IL-10 intervenes 75 with many processes that drive plaque progression, such as the 76 inhibition of NF- $\kappa \mathrm{B}$ signaling ${ }^{24}$ and the increase in efflux of 77 lipids from macrophages that prevents the formation of foam 78 cells. $^{25}$ IL-10 mainly acts by binding the IL-10 receptors (IL79 10R1 and IL-10R2), which induces their dimerization and 80 activates the receptor-associated kinases, janus kinase 1 (JAK1) 81 and tyrosine kinase $2(\mathrm{Tyk} 2)^{26,27}$ These activated kinases 82 phosphorylate signal transducer and activator of transcription 3 83 (STAT3), which leads to the transcription of downstream 84 genes that have been implicated in attenuating inflammation in 85 the M1 macrophage phenotype. ${ }^{28,29}$

86 Thus, the objective of this study was to identify a PBAE 87 capable of efficient transfection of IL-10 in primary endothelial 88 cells by screening six linear and branched PBAEs. The top89 performing PBAE NP was then applied in a proof-of-concept 90 anti-inflammatory study within the context of atherosclerosis. 91 The results of this study suggest that NP-mediated delivery of 92 an anti-inflammatory gene to ECs can attenuate inflammation 93 in macrophages whose accumulation and pro-inflammatory 94 phenotype drive atherosclerotic plaque progression.

\subsection{MATERIALS AND METHODS}

95 2.1. Materials. The following materials were purchased and used 96 as received: 1,4-butanediol diacrylate ("C"), 5-amino-1-pentanol 97 ("32"), trimethylol propane triacrylate ("TMPTA"), 1,3-diaminopro98 pane (DAP), 1,3-diaminopentane (PDA), anhydrous DMSO and 99 diethyl ether from Sigma-Aldrich, Canada, 1-(3-aminopropyl)-4100 methylpiperazine (PiP) and polyethylenimine (linear, $25 \mathrm{kDa}$ and 101 branched, $10 \mathrm{kDa}$ ) from Alfa Aesar (Haverhill, MA, USA), and 102 Lipofectamine 3000 from Thermo-Fisher Scientific Canada.

103 2.1.1. Plasmids. Detailed descriptions for the synthesis and 104 characterization plasmids used can be found in the Supporting 105 Information (SI).

106 2.2. Polymer Synthesis and Characterization. Linear PBAEs 107 were synthesized as reported previously ${ }^{9,30}$ by mixing monomers " $\mathrm{C}$ " and " 32 " at an acrylate-to-amine molar ratio of 1.2:1. Briefly, $345 \mathrm{mg} 108$ $(3.3 \mathrm{mmol})$ of "C" was mixed with $800 \mathrm{mg}(4 \mathrm{mmol})$ of prewarmed 109 (liquid) "32" without solvent in a 1-dram glass vial and stirred in an 110 oven at $90^{\circ} \mathrm{C}$ for $24 \mathrm{~h}$ to form the linear C32 base polymer. The C32 111 base polymer was end-capped with DAP or PDA by mixing $321 \mathrm{mg}$ of 112 $31.13 \%(\mathrm{w} / \mathrm{w}) \mathrm{C} 32$ in DMSO with $800 \mu \mathrm{L}$ of a $0.25 \mathrm{M}$ solution of 113 DAP or PDA in DMSO. For end-capping with PiP, $480 \mu \mathrm{L}$ of a 167114 $\mathrm{mg} / \mathrm{mL}$ solution of C32 in DMSO was added to $320 \mu \mathrm{L}$ of $0.5 \mathrm{M}$ PiP 115 in DMSO. All end-capping reactions were incubated overnight on a 116 shaker at room temperature and protected from light.

117

Branched PBAEs were formed by mixing $500 \mathrm{mg} / \mathrm{mL}$ solutions of 118 "C", prewarmed liquid "32", and TMPTA in anhydrous DMSO as 119 described previously. ${ }^{31}$ Amounts of $1.32 \mathrm{~g}$ of $(6.66 \mathrm{mmol})$ "C", $0.66 \mathrm{~g} 120$ $(6.4 \mathrm{mmol})$ of " 32 ", and $0.19 \mathrm{~g}(0.66 \mathrm{mmol})$ of TMPTA were mixed 121 together to maintain an acrylate-to-amine ratio of $1.2: 1$ with $10 \% 122$ branching. ${ }^{6}$ Monomers were stirred for $48 \mathrm{~h}$ in an oven at $90{ }^{\circ} \mathrm{C}$ and 123 then end-capped as mentioned above for the linear PBAEs. Linear and 124 branched PBAEs were precipitated in 3 volumes of ether, vortexed, 125 and centrifuged at $2000 \mathrm{~g}$ for $5 \mathrm{~min}$ before decanting the ether. Ether 126 purification was repeated $2 \times$, and polymers were dried under vacuum 127 for 24-48 h. Dry polymers were dissolved in anhydrous DMSO (100 128 $\mathrm{mg} / \mathrm{mL}$ ) and aliquoted into light-impermeable tubes and stored at 129 $-20{ }^{\circ} \mathrm{C}$ with desiccant. The polymer structures were confirmed with 130 ${ }^{1} \mathrm{H}$ NMR on a $400 \mathrm{MHz}$ AVIIIHD 400 spectrometer (Bruker, 131 Billerica, MA, USA) in chloroform-d (Cambridge Isotope Labo- 132 ratories Inc., Tewskbury, MA, USA), and the spectra were analyzed 133 with TopSpin (Bruker). $M_{\mathrm{w}}$ was determined by gel permeation 134 chromatography, which was performed on a Waters Breeze GPC 135 system (Milford, MA, USA) with 717 autosampler, 2414 refractive 136 index (RI) detector, and 1525 binary HPLC pump in anhydrous 137 tetrahydrofuran (Sigma-Aldrich, Canada). $M_{w}$ was determined against 138 polystyrene standards.

2.3. Nanoparticle Formation and Characterization. Nano- 140 particles were formed by diluting both pDNA and PBAEs in $25 \mathrm{mM} 141$ sodium acetate buffer $(\mathrm{pH}=5.2 \pm 0.2)$. PBAEs were diluted to 1.8 or 142 $3.6 \mathrm{mg} / \mathrm{mL}$ from $100 \mathrm{mg} / \mathrm{mL}$ stock solutions, while pDNA was 143 diluted to $60 \mu \mathrm{g} / \mathrm{mL}$. To obtain nanoparticles with PBAE:pDNA 144 ratios of 30 or $60 \mathrm{w} / \mathrm{w}$, one volume of each PBAE solution was added 145 to 1 volume of pDNA solution and vortexed $10 \mathrm{~s}$ followed by a 10146 min incubation before characterization or cell transfection. DLS 147 measurements were performed on a Brookhaven ZetaPals analyzer 148 (Holtsville, NY, USA). The nanoparticles were diluted $1 / 5$ in PBS for 149 size measurements and $1 / 5$ in $25 \mathrm{mM}$ acetate buffer for zeta potential 150 measurements.

2.4. Cell Culture. Pooled donor human umbilical vein endothelial 152 cells (HUVECs, Lonza \#C2519A) were cultured in growth medium 153 (1:1 mixture of EGM-2 (Lonza, Canada \#CC-3162) and DMEM-F12 154 (Wisent, QC, Canada) containing $10 \%$ FBS, $1 \%$ penicillin/ 155 streptomycin $(\mathrm{P} / \mathrm{S}))$. HUVECs were grown in culture plates coated 156 with $0.1 \%$ gelatin (EMD Millipore \#ES-006-B) and used before 157 passage 5 for all experiments. Murine endothelial cells ( $\mathrm{mECs}$ ) were 158 isolated from the lungs of C57BL/6 mice between 7 and 10 weeks of 159 age as described previously. ${ }^{32}$ Briefly, mice were sacrificed by $\mathrm{CO}_{2} 160$ asphyxiation, and lungs were macerated using surgical scissors under 161 sterile conditions and incubated $1 \mathrm{~h}$ at $37^{\circ} \mathrm{C}$ in serum-free RPMI 162 1640 (Wisent) supplemented with $1 \% \mathrm{P} / \mathrm{S}$ and $0.1 \%$ Collagenase A 163 (Roche Diagnostics, Laval, QC, Canada). The media containing tissue 164 chunks was passed through a $16 \mathrm{G}$ needle $15 \times$, and then a $100 \mu \mathrm{m}$ cell 165 strainer, and was centrifuged at $226 \mathrm{~g}$ for $5 \mathrm{~min}$. The cell pellet was 166 resuspended in growth media in a $75 \mathrm{~cm}^{2}$ flask precoated with $0.1 \% 167$ gelatin. The growth medium was refreshed every $2-4$ days until cells 168 reached confluency (7-10 days). mECs were then immuno-isolated 169 with sheep antirat IgG Dynabeads (Invitrogen, \#11035) that were 170 conjugated to a rat antimouse CD102 antibody (BD Biosciences 171 \#553325). Before isolation, $10 \mu \mathrm{L}$ magnetic beads were washed $3 \mathrm{X}$ in 172 $2 \%$ BSA-PBS and incubated with $10 \mu \mathrm{L}(10 \mu \mathrm{g})$ of CD102 antibody 173 for $3 \mathrm{~h}$ at $4{ }^{\circ} \mathrm{C}$. The washing step was repeated $3 \times$, and the beads 174 were added to mECs in T75 flasks followed by a $1 \mathrm{~h}$ incubation at 4175 ${ }^{\circ} \mathrm{C}$. Cells were then washed, trypsinized, and passed over a magnet 176 (EMD Millipore, Canada, PureProteome \#LSKMAGS15). Unbound 177 
<smiles>C=CC(=O)OCCCCOC(=O)C=C</smiles>

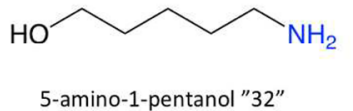

5-amino-1-pentanol "32"
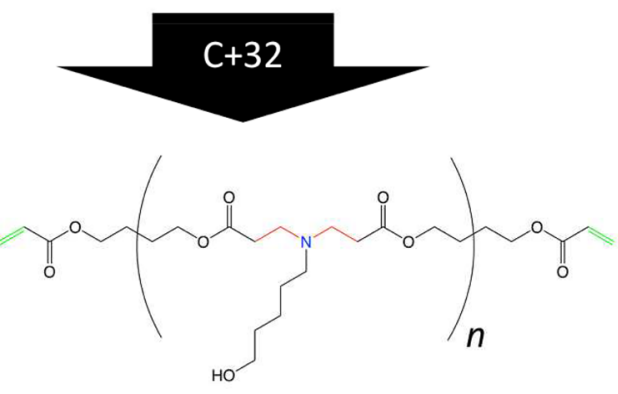

Linear C32 (L-X)

\section{Final End-Capping} With Amines<smiles>CNCCCN</smiles>

1,3-diaminopropane ( $\mathrm{X}=\mathrm{DAP}$ )

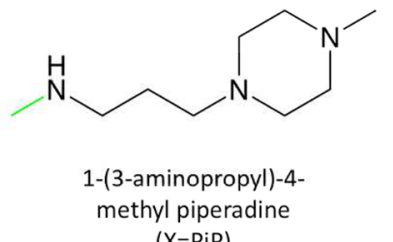

$(\mathrm{X}=\mathrm{PiP})$

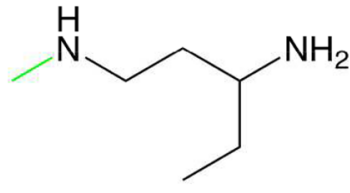

1,3-pentanediamine ( $X=P D A)$

Figure 1. Synthesis pathways used to create acrylate-terminated linear (L) and branched (B) C32 base polymers, which were then reacted with each small molecule amine (DAP, PiP, or PDA) to end-cap free acrylate groups.

178 cells and media were carefully removed, and magnetically fixed cells 179 were resuspended in growth media and plated onto gelatin-coated 180 flasks. After letting the isolated ECs grow until confluency (7-12 181 days), a second immunoisolation was performed as above to yield a 182 pure population of $\mathrm{mECs}$, which were used between passages 3 and 6 . 183 RAW264.7 macrophages were a gift from Talin Ebrahimian and were 184 cultured in RPMI 1640 (Wisent) supplemented with 10\% FBS and $1851 \% \mathrm{P} / \mathrm{S}$.

186 2.5. Flow Cytometry. For flow cytometry experiments, HUVECs 187 and mECs were plated in 12 -well plates precoated with a $0.1 \%$ gelatin 188 solution with 80000 cells/well for HUVECs and 65000 cells/well for 189 mECs $24 \mathrm{~h}$ before transfection. Nanoparticles formed between PBAEs 190 and pMAX-GFP were made as described in section 2.2 and added 191 directly to the wells (total of $3 \mu \mathrm{g}$ pGFP/well). The medium was 192 refreshed after $4 \mathrm{~h}$. Identical treatments with Lipofectamine 3000 and 193 polyethylenimine (PEI) (3:1 w/w ratio to $\mathrm{pDNA}$ ) per manufacturer 194 recommendations were used as positive controls, and pDNA alone in 195 acetate buffer was added as a negative control.

196 After $48 \mathrm{~h}$, cells were washed $2 \times$ with PBS, trypsinized, suspended 197 in FACS buffer (PBS + 2\% BSA), and centrifuged at $250 g$, for $5 \mathrm{~min}$, 198 at $4{ }^{\circ} \mathrm{C}$. The cells were washed once more with PBS before being 199 resuspended in FACS buffer. DAPI $(1.67 \mu \mathrm{g} / \mathrm{mL}$ final conc.) was 200 added 5-10 min before tubes were analyzed in the flow cytometer to 201 exclude dead cells. Flow experiments were performed on the 202 LSRFortessa (BD Biosciences, San Jose, CA, USA) flow cytometer 203 with $488 \mathrm{~nm}$ laser (530/30 filter) for GFP fluorescence and $405 \mathrm{~nm}$ 204 laser (450/50 filter) for DAPI. Data were then analyzed using FlowJo 205 (BD Biosciences). Singlets were gated in both forward and side scatter 206 to avoid analyzing aggregates.

207 2.6. Isolation of IL-10 Conditioned Media (CM). mECs were 208 seeded into gelatin-coated 6-well plates $\left(0.2 \times 10^{6}\right.$ cells/well $) 24 \mathrm{~h}$ 209 before nanoparticle transfection was performed using the same 210 protocol as mentioned above, but the pMAX-GFP plasmid was replaced with either the pIRES2-EGFP-IL10 or pIRES2-EGFP 211 (negative control plasmid without IL-10 coding insert) at $5 \mu \mathrm{g}$ of 212 pDNA/well. $72 \mathrm{~h}$ after transfection, supernatant was collected and 213 centrifuged at $23700 \mathrm{~g}$ and $4{ }^{\circ} \mathrm{C}$ for $15 \mathrm{~min}$. It was then filtered $(0.2214$ $\mu \mathrm{m})$ and stored at $-20^{\circ} \mathrm{C}$.

2.7. Quantitative Reverse Transcription PCR (qPCR). mRNA 216 was isolated from mECs $72 \mathrm{~h}$ after transfection. The cells were 217 washed once with cold PBS on ice and then scraped into cold RBC 218 lysis buffer (included in Geneaid kit, $100 \mu \mathrm{L}$ ). RNA was then purified 219 using the Total RNA Mini Kit (Geneaid) mentioned in the 220 Supporting Information (SI), transcribed into cDNA as mentioned 221 in the Supporting Information (SI), and qPCR was carried out using 222 SYBR green (Applied Biosystems, Foster City, CA, USA) as per 223 manufacturer protocols to quantify RNA copies on an ABI 7500 fast 224 real-time PCR system (Applied Biosystems). Gene expression was 225 compared to housekeeping ribosomal protein 16 (Rps16). The 226 following primers were used: IL-10 forward 5'- GTGATGCCC- 227 C A A G C T G A A - $3^{\prime}$ and rever se 5 $5^{\prime}-228$ CACGGCCTTGCTCTTGTTTT-3'; Rps16 forward 5'- ATCT- 229 CAAAGGCCCTGGTAGC-3' and reverse 5'- ACAAAGG- 230 TAAACCCCGATCC- $3^{\prime}$.

2.8. Attenuation of Inflammation in RAW264.7 Macro- 232 phages. RAW264.7 macrophages were seeded in a 48-well plate at 233 $62.5 \times 10^{3}$ cells/well in RPMI 1640. After sufficient time for the cells 234 to attach, at least $4 \mathrm{~h}$, they were serum starved in low serum RPMI 235 $1640(0.5 \%$ FBS, $1 \% \mathrm{P} / \mathrm{S})$ overnight. RPMI was removed, and 236 conditioned media containing IL-10 or not depending on $\mathrm{mEC} 237$ transfection conditions was then added $(1 \mathrm{~mL} /$ well $)$ in addition to 238 LPS when indicated $(10$ or $100 \mathrm{ng} / \mathrm{mL}$ ). The cells were returned to 239 the incubator for $24 \mathrm{~h}$. Media was then collected and stored at -20240 ${ }^{\circ} \mathrm{C}$ for ELISA assays of TNF $\alpha$ production.

2.9. Activation of Anti-Inflammatory Signaling in RAW264.7 242 Macrophages. RAW 264.7 macrophages were seeded into 6-well 243 


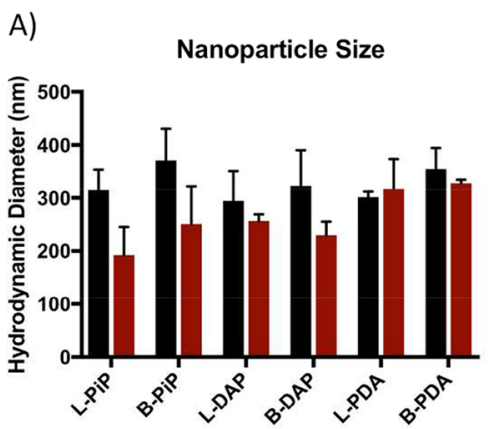

B)

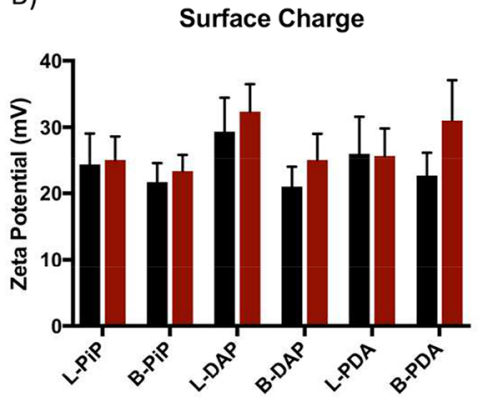

C)

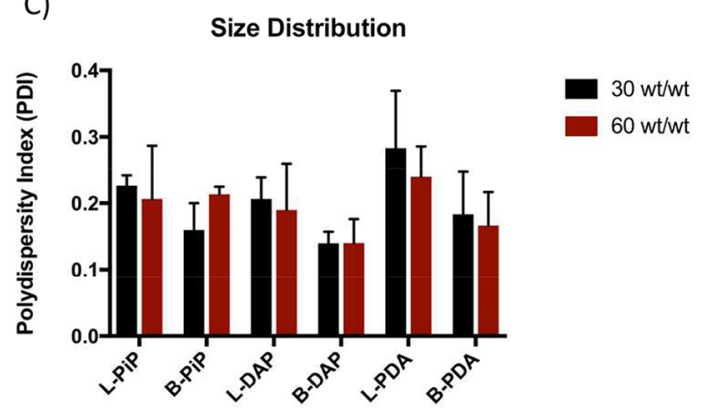

D)

\begin{tabular}{|c|c|c|c|}
\hline Parameter Measured & Size & Charge & PDI \\
\hline Branching & n.s. & n.s. & * $p=0.0104$ \\
\hline Polymer End Group & ${ }^{*} p=0.0463$ & n.s. & n.s. \\
\hline Wt/Wt ratio & ${ }^{*} p=0.0171$ & n.s. & n.s. \\
\hline
\end{tabular}

Figure 2. Nanoparticle physicochemical characterization via dynamic light spectroscopy displaying the (A) size, (B) surface charge, and (C) polydispersity of PBAE:pEGFP nanoparticles. (D) Table describing significant effects of fine-tunable properties (polymer branching, end group, or weight ratio of polymer:DNA). Statistical testing was performed using either paired $t$ tests (branching and wt ratio) or matched one-way ANOVA (polymer end group). $N=3$ for all, ns $=$ not significant, $*_{p}<0.05$.

244 plates $\left(0.5 \times 10^{6}\right.$ cells/well $)$ in RPMI $(10 \%$ FBS, $1 \%$ penicillin/ 245 streptomycin) and then serum starved overnight in low serum RPMI 246 (0.5\% FBS, $1 \%$ penicillin/streptomycin). An amount of $1 \mathrm{~mL}$ of CM 247 ( \pm IL-10 depending on EC transfection conditions) was added to 248 macrophages along with proteasome inhibitor MG-132 (Sigma249 Aldrich) to further inhibit protein degradation. Cells were incubated 250 for $4 \mathrm{~h}$ and then placed on ice, washed $3 \times$ with cold PBS, and scraped 251 into $80 \mu \mathrm{L}$ of cell lysis buffer, which contained the following 252 ingredients in $10 \mathrm{~mL}$ : final concentrations of $50 \mathrm{mM} \mathrm{Na}$ 253 pyrophosphate, $50 \mathrm{mM} \mathrm{NaF}, 5 \mathrm{mM} \mathrm{NaCl}, 5 \mathrm{mM} \mathrm{Na} 2$ EDTA, 5 $254 \mathrm{mM}$ EGTA, $10 \mathrm{mM}$ HEPES, and 0.5\% Triton X-100; 1 tablet 255 antiproteases cOmplete mini (Roche Diagnostics); and $\mathrm{Na}_{3} \mathrm{VO}_{4}(2$ $256 \mathrm{mM}$ final concentration). Cells were lysed using a probe tip sonicator 257 (Sonics Vibra-cell, Newtown, CT, USA) for $3 \mathrm{~s}$ ( $1 \mathrm{~s}$ on, $1 \mathrm{~s}$ off) and 258 then centrifuged $23700 \mathrm{~g}$, at $4{ }^{\circ} \mathrm{C}$, for $15 \mathrm{~min}$. Supernatants were 259 placed in a fresh tube and stored until use at $-80{ }^{\circ} \mathrm{C}$. An amount of $26030 \mu \mathrm{g}$ of total protein (as quantified by BCA assay) was added per 261 well in a $10 \%$ SDS-PAGE gel and transferred to nitrocellulose 262 membranes. The following antibodies were used as per manufacturer 263 instructions: rabbit antiphospho-STAT3 (Y705, Cell Signaling 264 Technologies \#9145, 1/2000), mouse anti-STAT3 (Transduction 265 Laboratories \#610190, 1/1000), antimouse or antirabbit HRP (1/ 266 2000, BioRad \#172-1011 and 170-6515, respectively). Visualization 267 was performed using Western Lightning ECL Pro (PerkinElmer) 268 chemiluminescent substrate, and membranes were imaged on a 269 ChemiDoc XRS+ (BioRad, Hercules, CA, USA). Band intensities 270 were quantified using ImageJ.

271 2.10. Enzyme-Linked Immunosorbent Assay (ELISA). ELISA 272 kits were obtained from Thermo Fisher Scientific, and assays were 273 performed as per manufacturer instructions on cell supernatants 274 undiluted or diluted 1:10 in EliSPOT diluent (included in kit) to be 275 in sensitivity ranges: $10-150 \mathrm{pg} / \mathrm{mL}$ for IL-10 (\#88-7106-22) and $27610-300 \mathrm{pg} / \mathrm{mL}$ for mouse TNF $\alpha$ (\#88-7324-22).

277 2.11. Statistics. Statistical analysis was performed in Graphpad 278 Prism 7 software (Graphpad Software, La Jolla, CA, USA). Paired 279 student's $t$ tests and/or matched one-way ANOVA were used to test 280 the effects of branching, polymer wt/wt ratio to pDNA, and end 281 group chosen on physicochemical properties, cell transfection, and 282 viability. One-way ANOVA with Sidak's multiple comparisons test 283 was used to test transfection conditions for all PBAEs against 284 lipofectamine as well as for cell viability against pDNA only control. 285 Unpaired student's $t$ test was used to compare effects of $\mathrm{CM} \pm \mathrm{IL}-10$ for qPCR, ELISA, and Western blot results. All data are presented as 286 mean \pm SEM with $p<0.05$ denoted "*” and $p<0.01$ denoted "\#”. 287

\subsection{RESULTS}

3.1. Synthesis and Characterization of Linear and 288 Branched PBAEs. PBAEs are formed via the Michael's 289 addition polymerization reaction "neat" without the use of 290 catalysts or other reagents. The syntheses were confirmed via 291 ${ }^{1} \mathrm{H}$ NMR spectroscopy. Base polymer end-capping was verified 292 by the disappearance of acrylate peaks around 5.0-5.8 ppm 293 (Figure S1). ${ }^{33}$ The $M_{\mathrm{w}}$ was then quantified by gel permeation 294 chromatography (GPC). The $M_{\mathrm{w}}$ 's of linear and branched 295 PBAEs were $5.3 \mathrm{kDa}$ (polydispersity index (PDI) of 1.49) and 296 $6.2 \mathrm{kDa}$ (PDI of 1.91), respectively (Table S1). 297

3.2. Synthesis and Characterization of PBAE:pDNA 298 NPs. NPs were formed with the 6 PBAEs at two different 299 weight ratios of polymer to pDNA to compare the effect of 3300 different parameters on NP physicochemical properties and 301 transfection efficiency in primary endothelial cells. These 302 parameters were (1) the effect of branching the polymer 303 structure, (2) the weight ratio of polymer to pDNA, and (3) 304 the choice of end-capping amine group (Figure 1). $305 \mathrm{ft}$

Nanoparticles are formed via the electrostatic interactions 306 between cationic PBAEs and anionic plasmid DNA. Because of 307 the excess of cationic PBAEs to pDNA in complexation, 308 nanoparticles are cationic. Two weight ratios of polymer:- 309 pDNA were chosen based on preliminary experiments. It was 310 discovered that of $10,30,60$, and $100 \mathrm{w} / \mathrm{w}$ ratios of PBAEs to 311 pDNA, 30 and $60 \mathrm{w} / \mathrm{w}$ bound all pDNA available and 312 prevented its migration in an agarose gel electrophoresis test 313 for all PBAEs (data not shown), whereas 10 and $100 \mathrm{w} / \mathrm{w}$ were 314 unable to complex fully with pDNA. Nanoparticles formed 315 between all PBAEs and pMAX-GFP were used for 316 physicochemical characterization measurements, although 317 those formed with the pIRES2-EGFP-IL10 plasmid had similar 318 properties for the same PBAE (data not shown).

319

Figure 2 shows the physicochemical properties of NPs $320 \mathrm{f}_{2}$ including which formulation (i.e., fine-tunable) parameters 321 have a significant impact on physicochemical properties. The 322 
A)

Cell Viability HUVECs

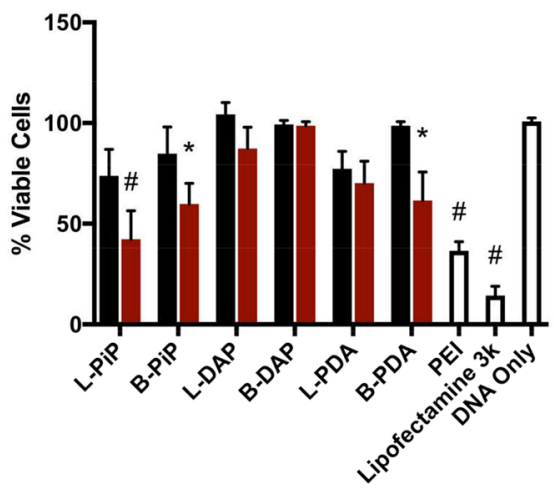

B)

Cell Viability mECs

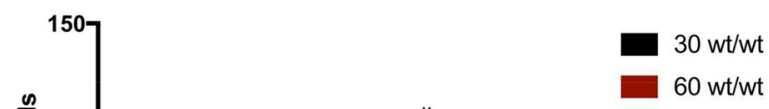

Figure 3. Cell viability of PBAE:pEGFP nanoparticles in two primary endothelial cell lines: (A) HUVECs and (B) mouse mECs as measured by DAPI exclusion via flow cytometry. $N \geq 3$ for HUVECs, and $N=$ mECs from at least 4 mice. $* p<0.05$ and $\# p<0.01$ when compared to DNA only control.
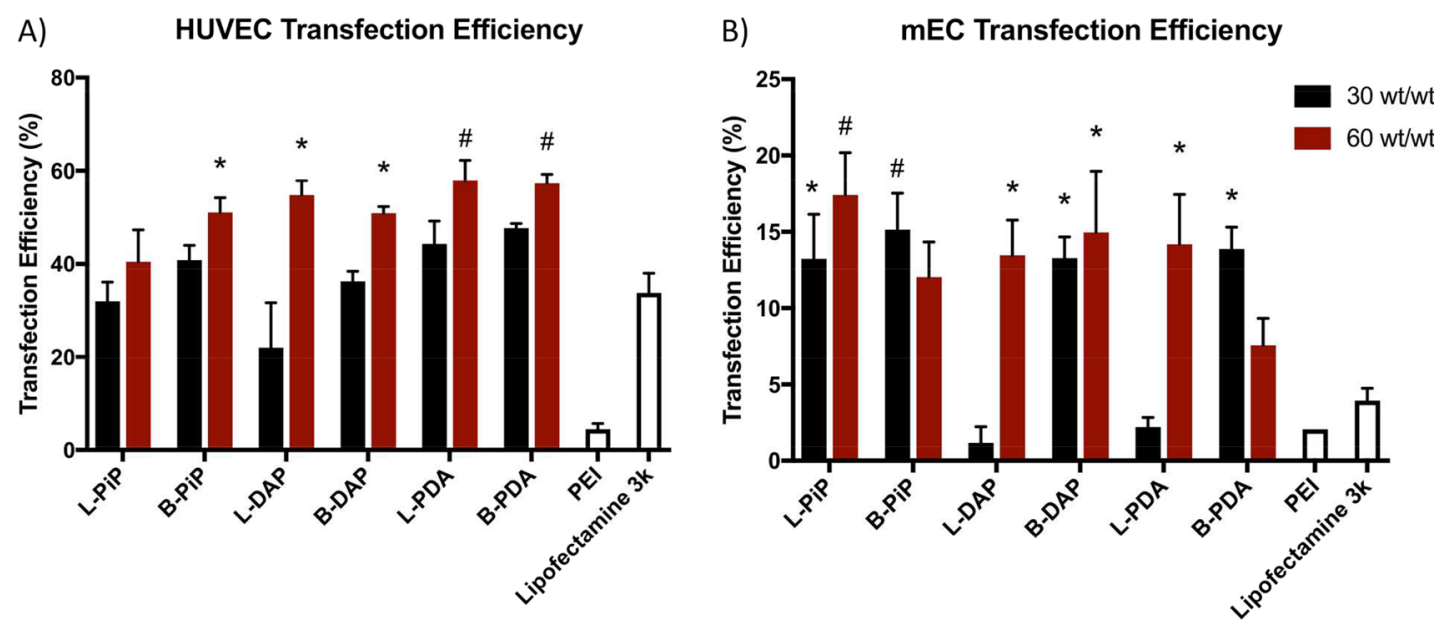

Figure 4. Transfection efficiency of PBAE:pEGFP nanoparticles in two primary endothelial cell lines: (A) HUVECs and (B) mECs as measured by percentage of GFP+ cells over other living (DAPI-) cells via flow cytometry. $N \geq 3$ for HUVECs, and $N=$ mECs from at least 4 mice. $* p<0.05$ and $\# p<0.01$ when compared to Lipofectamine 3k via one-way ANOVA with Sidak's multiple comparison's test.

323 size of NPs was the most variable parameter (Figure $2 \mathrm{~A}$ ), being 324 influenced by both the end group chosen and the $\mathrm{w} / \mathrm{w}$ ratio of 325 PBAE:pDNA. Interestingly, with the three controllable NP 326 formation parameters tested, none led to a significant change 327 in the surface charge of particles (Figure 2B). Similarly, the 328 polydispersity index (PDI) was only significantly affected by 329 branching the structure of PBAEs wherein branched PBAEs 330 formed more monodisperse nanoparticles (Figure 2C). These 331 results are summarized in Figure 2D.

$332 \quad 3.3$. Effects of Polymer Structure and Amount on NP 333 Toxicity and Transfection Efficiency in Primary Endo334 thelial Cells. To acquire a more complete understanding of 335 how PBAEs behave in primary ECs, two types of ECs were 336 chosen. HUVECs have been used before in transfection studies 337 and served to relate the findings of this study with those in the 338 literature. Mouse pulmonary ECs (mECs) were chosen to 339 determine the limits of PBAE transfection capabilities in a new 340 and challenging primary mouse EC model.

341 First, the viability of ECs was assayed after exposure to 342 PBAE:pGFP NPs for all polymers and controls. The majority 343 of PBAE:pEGFP nanoparticles did not cause significant cell 344 death in either HUVECs (Figure 3A) or mECs (Figure 3B). In 345 HUVECs, L-PiP-60, B-PiP-60, and B-PDA-60 displayed 346 significant toxicity over control. mECs seemed to be more robust as only B-PDA-60 resulted in toxicity. Both cell types 347 experienced significant toxicity from standard transfection 348 reagent PEI, whereas commercial reagent Lipofectamine was 349 significantly toxic in HUVECs only. These results underline 350 the importance of screening materials in specific cell types as 351 they may react differently.

352

To characterize the transfection efficiency of the polymers, 353 NPs at both 30 and $60 \mathrm{w} / \mathrm{w}$ ratios were freshly prepared using 354 the pMAX-GFP plasmid and added to both HUVECs and 355 mECs. In Figure 4A, the transfection efficiency in HUVECs $356 \mathrm{f4}$ was markedly higher ( $\sim 60 \%$ for best performing PBAEs) than 357 in mECs $(\sim 15 \%$, Figure $4 \mathrm{~B})$. L-PiP-60 was most efficient for 358 mECs, whereas the 60 wt ratio PDA-terminated PBAEs were 359 most efficient for HUVECs (L-PDA-60 and B-PDA-60). 360 Branching the structure of PBAEs had little effect on their 361 transfection efficiency. Some slight improvements were seen 362 with branching for HUVECs (-PiP and -DAP polymers) but 363 not in mECs. However, at a $30 \mathrm{w} / \mathrm{w}$ ratio, L-DAP and L-PDA 364 were not efficient in transfecting $\mathrm{mECs}$, but the branched 365 versions showed significant improvement (Figure 4B). Five of 366 the PBAEs showed transfection efficiency significantly higher 367 than the positive control Lipofectamine 3k for HUVECs. 368

All transfection methods (Lipofectamine and PBAEs) were 369 less efficient in mECs than HUVECs; however, nearly all (8/ 370 
371 12) PBAEs showed significantly greater efficiency than 372 Lipofectamine (Figure 4B). Polyethylenimine (PEI, linear 25 $373 \mathrm{kDa}$ ) was also included as it is a synthetic polymer often used 374 in gene transfection studies, but it was not very efficient for 375 primary endothelial cells.

376 Table 1 summarizes the effect of NP structure and amount 377 (wt ratio) on cell viability and transfection efficiency in the two

Table 1. Contributions of Fine-Tunable Parameters of NP Formation on Cell Viability and Transfection Efficiency for HUVECs and mECs ${ }^{a}$

$\begin{array}{lcccc}\text { parameter } & \begin{array}{c}\text { cell } \\ \text { viability } \\ (\mathrm{mEC})\end{array} & \begin{array}{c}\text { transfection } \\ \text { efficiency } \\ (\mathrm{mEC})\end{array} & \begin{array}{c}\text { cell viability } \\ \text { (HUVEC) }\end{array} & \begin{array}{c}\text { transfection } \\ \text { efficiency } \\ \text { (HUVEC) }\end{array} \\ \begin{array}{l}\text { branching } \\ \text { polymer } \\ \text { end }\end{array} & 0.2319 & 0.4767 & 0.1688 & 0.1138 \\ \text { group } & 0.6933 & 0.2900 & * 0.0118 & 0.0971 \\ \text { wt/wt ratio } & * 0.021 & 0.3203 & * 0.0188 & * 0.0101\end{array}$

${ }^{a}$ Data are $p$-values showing significant differences between groups (parameters) as measured by paired student's $t$-test (branching and wt/wt ratio) and by matched one-way ANOVA (polymer end group), $N \geq 3$ for HUVECs and $N=$ mECs from at least 4 mice $*_{p}<0.05$.

378 types of primary endothelial cells investigated. Integrating the 379 results for transfection efficiency, cell viability, and nanoparticle 380 properties, the L-PiP-30 polymer was selected for anti381 inflammatory gene therapy studies involving IL-10 in mECs. 382 There was a general increase in transfection with 60 wt ratios 383 for PBAEs in HUVECs accompanied by an increase in cell 384 death, but this was not observed in mECs (Table 1).

385 3.4. $m E C$ Transfection and Production of IL-10 Using 386 L-PiP-30 Nanoparticles. Detailed synthesis and description 387 of the pIRES2-EGFP-IL10 plasmid are given in the Supporting 388 Information (SI). This plasmid was used as a means to 389 produce the anti-inflammatory protein IL-10 in primary 390 endothelial cells. The production of IL-10 was visualized in 391 HUVECs via GFP from the same RNA transcript as IL-10 in 392 this plasmid (Figure S2). Since HUVECs had higher 393 transfection efficiencies, they also produced higher amounts 394 of IL-10 than mECs $(\sim 35 \mathrm{ng} / \mathrm{mL}$ vs $\sim 0.8 \mathrm{ng} / \mathrm{mL}$ in $\mathrm{mECs})$ 395 (Figure S3). However, mECs were the focus of anti396 inflammatory studies as they are a new ex vivo cell type. To 397 first characterize the production of IL-10 by transfected mECs, 398 quantitative real-time PCR (qPCR) was performed after $72 \mathrm{~h}$ 399 of transfection with L-PiP-30. Figure 5 shows a significant increase in IL-10 production when mECs are transfected using 400 L-PiP-30 PBAE nanoparticles containing the pIRES2-EGFP- 401 IL10 plasmid (NPs + IL-10) vs the same plasmid without the 402 IL-10 insert (NPs-IL-10). A significant increase in IL-10 403 mRNA production was observed (Figure 5A) when normal- 404 izing to the expression of housekeeping Rps16 protein. This 405 translated to a significant increase in IL-10 protein production 406 $(851 \pm 39 \mathrm{pg} / \mathrm{mL})$ in the conditioned media from transfected 407 mECs after $72 \mathrm{~h}$ (Figure 5B) as measured by ELISA. 408

3.5. Conditioned Media (CM) from IL10-Transfected 409 Primary Endothelial Cells Activates Anti-Inflammatory 410 Pathways in RAW264.7 Macrophages. IL-10 was success- 411 fully produced via L-PiP-30 NP transfections at both the 412 mRNA and protein level in mECs. Thus, the anti-inflammatory 413 activity of CM containing IL-10 was evaluated in mouse 414 macrophages via functional assays. First, a prototypical 415 signaling pathway of IL-10 was examined, namely, the 416 phosphorylation of STAT3. ${ }^{34} \mathrm{CM}$ from mECs transfected 417 with pIRES2-EGFP plasmid (CM -IL10) or pIRES2-EGFP- 418 IL10 plasmid (CM + IL10) was added to RAW264.7 419 macrophages. After $4 \mathrm{~h}$ in CM + IL10, there was a 2 -fold 420 increase in the phosphorylation of STAT3, normalized to the 421 expression of total unphosphorylated STAT3 (Figure 6). Thus, 422 f6 media derived from IL10-transfected mECs activated a 423 canonical IL-10 anti-inflammatory signaling pathway in 424 macrophages.

3.6. CM from IL10-Transfected Primary Endothelial 426 Cells Reduces Inflammation in Stimulated RAW264.7 427 Macrophages. After verifying that CM from IL10-transfected 428 mECs activates anti-inflammatory pathways in macrophages, it 429 was then determined if a functional macrophage response to 430 pro-inflammatory stimuli could be observed. Within the 431 atherosclerotic plaque, activated (pro-inflammatory) macro- 432 phages secrete damaging cytokines, such as $\mathrm{TNF} \alpha$, that 433 perpetuate inflammation and destabilize the plaque. For 434 macrophage activation, lipopolysaccharide (LPS) derived 435 from bacterial cell walls was chosen. LPS induces a well- 436 characterized hyperactive inflammatory response via toll-like 437 receptors 2 and 4 (TLR-2/-4) in RAW264.7 macrophages. $^{35} 438$ When macrophages were cultured in CM -IL10 without LPS 439 stimulation, there was a very low baseline of TNF $\alpha$ production 440 as measured by ELISA $(41 \pm 14 \mathrm{pg} / \mathrm{mL}$ ) (Figure 7). TNF $\alpha 441 \mathrm{f} 7$ levels increased to $1167 \pm 351 \mathrm{pg} / \mathrm{mL}$ when $10 \mathrm{ng} / \mathrm{mL}$ of LPS 442 (+) was added and substantially increased to $2060 \pm 195 \mathrm{pg} / 443$ $\mathrm{mL}$ when $100 \mathrm{ng} / \mathrm{mL}$ of LPS was added $(++)$, indicating a 444 dose-dependent response (Figure 7, black bars). CM + IL10 445

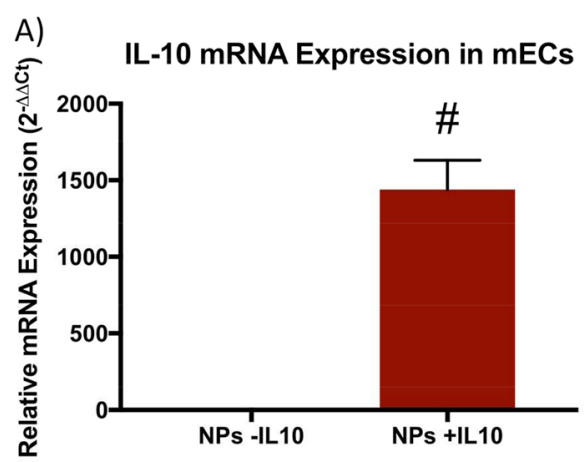

B)

\section{IL-10 Protein Production by mECs}

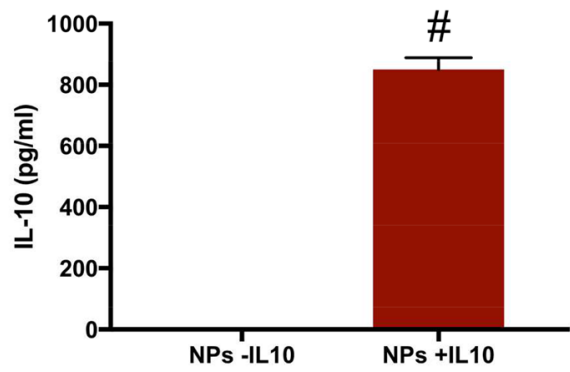

Figure 5. Quantitation of IL-10 production in mECs following transfection with L-PiP-30 and pIRES2-EGFP-IL10 or pIRES2-EGFP plasmids. (A) mRNA production was normalized to housekeeping gene Rps16 via qPCR. (B) IL-10 protein levels were detected in supernatant via ELISA. All analysis was done $72 \mathrm{~h}$ after transfection $(N=\mathrm{mECs}$ from at least 4 mice, $\# p<0.01$, via student's $t$ test $)$. 

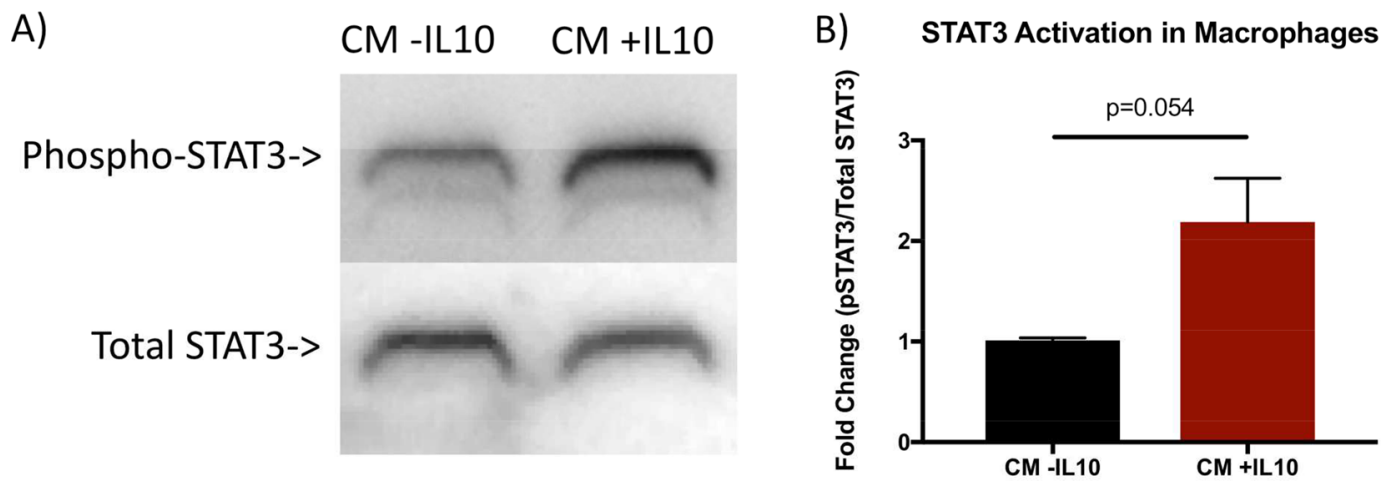

Figure 6. Conditioned media from IL10-transfected mECs increases phospho-STAT3 in macrophages. (A) Expression of phosphorylated STAT3 normalized to total nonphosphorylated STAT3. Image representative of three independent experiments, quantified in (B). Statistics evaluated by student's $t$-test with $N=\mathrm{CM}$ from 3 sets of mECs on 3 independent batches of RAW264.7 macrophages.

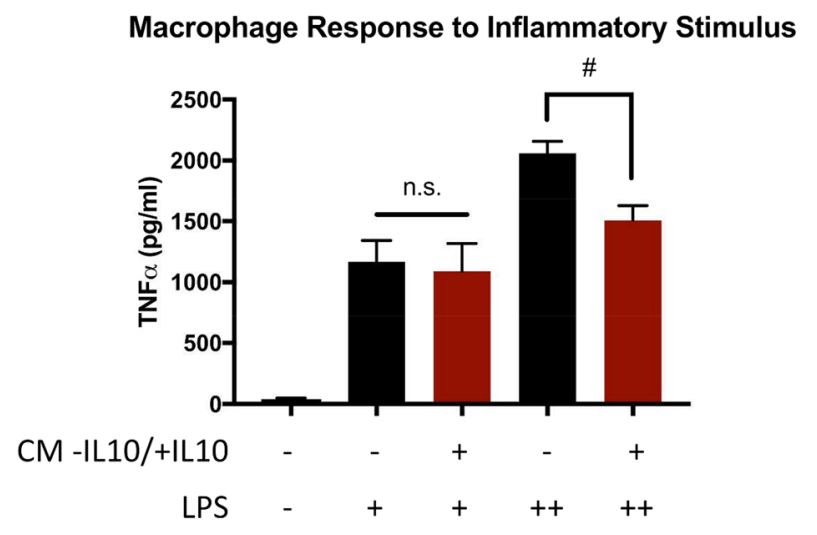

Figure 7. TNF $\alpha$ secretion by RAW264.7 macrophages in CM in response to LPS stimulation for $24 \mathrm{~h} .10 \mathrm{ng} / \mathrm{mL}$ LPS $(+) ; 100 \mathrm{ng} / \mathrm{mL}$ LPS $(++)$. Data are mean \pm SEM, \#p $<0.01$ from one-way ANOVA with Dunnett's Multiple Comparisons test, $N=$ CM from 4 sets of mECs. TNF $\alpha$ levels measured via ELISA.

446 had no impact on TNF $\alpha$ production in response to $10 \mathrm{ng} / \mathrm{mL}$ 447 of LPS. However, CM + IL10 significantly attenuated TNF $\alpha$ 448 production in macrophages stimulated with $100 \mathrm{ng} / \mathrm{mL}$ of LPS $449(p<0.01)$, compared to CM-IL10. Hence, CM + IL10 450 displayed a high potential to attenuate the production of pro451 inflammatory cytokines in stimulated macrophages.

\subsection{DISCUSSION}

452 Biodegradable polymers, and PBAEs specifically, offer unique 453 advantages by virtue of their combinatorial and solvent-free 454 synthesis which can allow for transfection and toxicity 455 investigations in a variety of cell types. Along these lines, a 456 small library of 6 PBAEs were synthesized by adding 3 different 457 end-capping groups (PiP, DAP, and PDA) onto the linear C32 458 base polymer (L) or the branched C32-TMPTA base polymer 459 (B). The molecular weight of the linear PBAEs was similar to 460 previous reports in the literature, while the branched PBAEs in 461 this study were slightly smaller $(6.2 \mathrm{kDa}$ vs $10+\mathrm{kDa}$ reported 462 to be successful by others $\left.{ }^{36-40}\right)$. However, studies have shown 463 that linear PBAE performance is most affected by the end 464 group chosen in easier-to-transfect cells, ${ }^{30}$ whereas molecular 465 weight may play a larger role in branched PBAEs. ${ }^{41}$ High 466 performing end groups for branched PBAEs have included 467 1,11-diamino-3,6,9-trioxaundecane ${ }^{6}$ and 3-morpholinopropyl468 amine. $^{37,38,41}$
The end groups in this study were selected for their ability to 469 provide consistently high transfection efficiencies in various 470 cell types ${ }^{30,42,43}$ including endothelial cells. Similarly, the 471 branched version of C32 was included in the library to test 472 whether branching could improve endothelial cell transfection 473 as branched PBAEs have been shown to increase transfection 474 efficiency over their linear counterparts in other cell types. ${ }^{6} 475$ Thus, the polymer library in this study consisted of 3 top- 476 performing linear PBAEs (L-PiP, L-DAP, L-PDA) identified 477 from the literature (involving ECs where available ${ }^{7,9,43}$ ) and 478 the branched counterparts, some of which were synthesized for 479 the first time here (B-PiP and B-PDA). The effect of polymer 480 amount was also considered by testing each PBAE at two 481 different weight ratios to DNA since transfection generally 482 increases with increasing polymer amount; however, toxicity 483 generally increases as well. ${ }^{44}$ In terms of the physicochemical 484 properties of NPs, it was discovered that both the polymer:- 485 pDNA wt ratio and end group chosen could significantly 486 influence NP size, whereas no parameter influenced the surface 487 charge of NPs, in agreement with others. ${ }^{30}$ Nanoparticles are 488 considered very small (10-100 $\mathrm{nm}$ range); however, 489 polyplexes are often larger $(150+\mathrm{nm})$ and have still seen 490 success in vivo. $^{45}$ Larger particles may extravasate more 491 efficiently to the endothelium in blood flow which holds 492 promise for new strategies to target atherosclerosis using 493 polyplexes. $^{46,47}$ In terms of polyplex dispersity, a significant 494 decrease was observed when moving from linear to branched 495 PBAEs, indicating that branching could help achieve more 496 monodisperse NPs. This has not been reported in studies 497 involving branched PBAEs as PDI does not seem to be a 498 parameter explored in previous studies.

Few PBAEs significantly increased primary EC death in this 500 study, and only at the higher wt/wt ratio of $60: 1$ polymer to 501 DNA. While the linear PBAEs are often used at 30:1 and 60:1, 502 previous studies involving branched PBAEs ${ }^{37,38}$ typically used 503 lower ratios $(10: 1,20: 1$, and 30:1). However, wt/wt ratios of 504 30 and 60:1 were chosen for branched PBAEs in this study for 505 direct comparison with linear counterparts. It is possible that 506 branched PBAEs could be more effective in mECs at lower 507 doses $(10: 1$ or $20: 1)$, and this was one limitation to the study. 508 Despite the many weight ratios that have been tested in vitro, 509 the corresponding in vivo doses of NPs rarely exceed $30 \mathrm{w} / \mathrm{w} 510$ for the typical $25-50 \mu \mathrm{g}$ plasmid DNA in the literature. ${ }^{48-50} 511$

Interestingly, branching the structure of PBAEs led to few 512 differences in physicochemical characteristics or transfection 513 efficiency/toxicity of these nanoparticles in primary ECs. It is 514 
515 possible that these cells present higher transection barriers 516 even for the branched polymers, which were shown to be 517 superior to linear PBAEs in easier-to-transfect cells such as 518 HEK293, CHO, and COS-7 cells. ${ }^{31}$ Indeed, the best 519 performing polymers in this study reached a maximum of $52060 \%$ transfection efficiency in HUVECs, a result shared by 521 others. ${ }^{9,51}$ In addition, the HUVECs seemed to respond more 522 to branched PBAEs (Table 1), and the most efficient polymer 523 for HUVECs was not the best for mECs. As mECs are taken 524 directly from mice in an in-house protocol and HUVECs are 525 from a commercial provider, differences in their responses to 526 potential treatments can be expected. Nevertheless, branching 527 the base polymer structure was able to facilitate transfection in 528 some conditions where linear PBAEs were unsuccessful in 529 mECs (L-DAP-30 and L-PDA-30). Taken together, these data 530 indicate a high dependence of cell type on transfection 531 efficiency and the degree to which it can be enhanced.

532 As mentioned earlier, there were few statistical differences 533 between the branched and linear PBAEs in terms of NP 534 properties, cell viability, and cell transfection, although the B$535 \mathrm{PiP}$ polymer performed slightly better than the L-PiP in $\mathrm{mEC}$ 536 transfection $(17 \pm 3 \%$ vs $13 \pm 3 \%)$. However, this was not a 537 significant difference, and the choice for L-PiP was made more 538 based on minor advantages of L-PiP over B-PiP. For example, 539 L-PiP generally formed smaller nanoplexes with pDNA $(\sim 300$ $540 \mathrm{~nm}$ for L-PiP vs $\sim 380 \mathrm{~nm}$ for B-PiP), which could be desirable 541 for future in vivo studies. In addition, as L- and B-PiP 542 performed nearly identically, L-PiP only uses two monomers 543 and no organic solvents for its synthesis, which can save money 544 and waste. Therefore, L-PiP was chosen as the lead polymer for 545 subsequent anti-inflammatory experiments involving IL-10 546 gene delivery.

547 IL-10 has been widely recognized as a potent anti548 inflammatory protein with high therapeutic potential. Known 549 originally as cytokine synthesis inhibitory factor, its involve550 ment in the resolution of inflammation is ubiquitous in 551 infection, $^{52}$ fibrosis, ${ }^{53}$ atherosclerosis, ${ }^{54}$ and many other 552 pathologies mainly through acting on macrophages. To deliver 553 IL-10, the pIRES2-EGFP plasmid was chosen, which allows for 554 translation of the gene of interest along with a GFP reporter. 555 Though GFP expression in the pIRES2-EGFP plasmid is not as 556 high as in typical reporter plasmids, ${ }^{55}$ the GFP expression can 557 be used to monitor successful transfections under the 558 microscope in live cells. The production of IL-10 was also 559 confirmed at both the mRNA and protein level.

560 The main pathway activated and responsible for the anti561 inflammatory effects of IL-10 is STAT3, which acts to both 562 produce anti-inflammatory proteins ${ }^{28,56}$ and as a negative 563 feedback element, shutting down the inflammatory response. ${ }^{29}$ 564 CM from IL10-transfected cells induced a robust response in 565 RAW264.7 macrophages in the form of STAT3 phosphor566 ylation. Some pSTAT3 was observed in response to CM from 567 GFP control cells as well, indicating that the mEC secretome 568 may also activate STAT3, though not as potently as in IL10569 transfected cells. However, the EC media itself (which contains 570 many growth factors) did not activate STAT3, showing the 571 specificity of EC-derived factors (data not shown).

572 Though significant, the effects of IL-10 within conditioned 573 media in this study were not as large as those reported in the 574 many studies using RAW264.7 macrophages and recombinant 575 IL-10 protein. Clarke et al. observed that $1 \mathrm{ng} / \mathrm{mL}$ or higher of $576 \mathrm{IL}-10$ reduced the production of $\mathrm{TNF} \alpha$ in macrophages 577 incubated with $10 \mathrm{ng} / \mathrm{mL}$ LPS. ${ }^{57}$ In contrast, IL-10 measured in $\mathrm{mEC} \mathrm{CM}$ in this study reached only $\sim 0.8 \mathrm{ng} / \mathrm{mL}$, and a 578 significant anti-inflammatory response was only observed upon 579 LPS stimulation at $100 \mathrm{ng} / \mathrm{mL}$. Interestingly, no effect on 580 $\mathrm{TNF} \alpha$ secretion was observed after macrophages were 581 incubated in CM + IL10 and a lower dose of LPS (10 ng/ 582 $\mathrm{mL}$ ). This may suggest that some threshold value of 583 inflammation must be achieved before evidence of IL-10 584 activity can be seen or that IL-10 can only lower TNF $\alpha 585$ secretion to a certain level. Inflammatory signaling thresholds 586 have been discussed in the literature previously. ${ }^{58}$ It is unlikely 587 that the timing of IL-10 exposure is a determining factor in the 588 poor response to LPS at $10 \mathrm{ng} / \mathrm{mL}$ since, both in this study 589 (data not shown) and others, ${ }^{19}$ administering IL-10 (recombi- 590 nant or in CM from mECs) $15 \mathrm{~min}$ to $2 \mathrm{~h}$ prior to LPS 591 produced the same subsequent reduction in TNF $\alpha$. 592

In terms of mechanism of action, IL-10 CM-mediated 593 attenuation of $\mathrm{TNF} \alpha$ production in response to LPS 594 implicated no change in TNF $\alpha$ mRNA levels (data not 595 shown), indicating a possible post-translational effect. Clarke et 596 al. ${ }^{57}$ reported similar findings. In fact, the mRNA levels of 597 MMP-9 and ICAM-1 were also examined in this study and 598 found to be elevated by LPS but similarly unchanged in CM + 599 IL10 (data not shown). This contrasts with data from 600 Hovsepian et al., ${ }^{52}$ who observed an IL-10-dependent decrease 601 in mRNA levels of TNF $\alpha$, as well as IL-6, MMP-9, and MMP-2 602 after infection with T. Cruzi in cardiomyocytes. Perhaps 603 differences are due to the inflammatory stimulation method 604 (whole bacteria vs LPS) or cell type (cardiac muscle cells vs 605 ECs). These results further outline the complexity and exciting 606 capabilities of the immune response.

607

\subsection{CONCLUSIONS}

This study compared the effects of branching, end-group 608 modification, and weight ratio of polymer to pDNA on NP 609 formation and physicochemical properties. The small library of 610 6 different PBAE NPs were also evaluated for DNA 611 transfection efficiency and viability in two types of primary 612 endothelial cells (mECs and HUVECs) as models for difficult- 613 to-transfect cell types. In mECs, none of the varied parameters 614 significantly affected transfection efficiency, while in HUVECs, 615 the ratio of polymer to DNA in the NPs had a significant effect 616 on transfection efficiency with higher ratios resulting in better 617 transfection, but also more toxicity. The viability of both 618 HUVECs and mECs generally decreased with increasing 619 polymer to DNA ratios, while the polymer's end-capping 620 group affected only the HUVECs' viability. Therefore, the 621 HUVECs were more responsive to changes in polymer 622 properties than the mECs. The top-performing PBAE for 623 HUVECs (B-PiP-60) was different than that for mECs (L-PiP- 624 30). Hence, screening a small library of PBAEs such as this was 625 useful as even these two types of primary endothelial cells 626 showed marked differences in gene expression and toxicity. 627

The best-performing PBAE in mECs was used to deliver the 628 IL-10 gene, which resulted in production of IL-10 at both the 629 mRNA and protein level. When CM from IL-10 transfected 630 mECs was applied to murine macrophages, a 2-fold increase in 631 the phosphorylation of STAT3 was observed. Furthermore, the 632 IL-10 containing CM caused a $25 \%$ reduction in the secretion 633 of TNF $\alpha$ by LPS-stimulated macrophages. This study was a 634 promising first step toward finding an optimal material for the 635 nonviral transfection of primary ECs and the modification of 636 their immediate environment via protein secretion. ECs are 637 involved in various diseases, and their immediate environment 638 
639 often contains important effector cells like macrophages, such 640 as in the case of atherosclerosis. Though nonviral DNA 641 delivery has been utilized in atherosclerosis to lower lipid 642 levels, ${ }^{59}$ no such anti-inflammatory gene delivery strategies 643 have been attempted.

\section{ASSOCIATED CONTENT}

\section{S Supporting Information}

646 The Supporting Information is available free of charge on the 647 ACS Publications website at DOI: 10.1021/acsabm.8b00342.

648 Experimental procedures for the synthesis of all plasmids

649 used, polymer characterization data ( ${ }^{1} \mathrm{H}$ NMR spectro650 graphs), molecular weight data table (GPC), HUVEC 651 expression of pIRES2-EGFP-IL10 via fluorescence 652 microscopy, and IL-10 production via PBAE transfection 653 of HUVECs (PDF)

\section{AUTHOR INFORMATION}

\section{Corresponding Authors}

656 *E-mail: maryam.tabrizian@mcgill.ca.

657 *E-mail: stephanie.lehoux@mcgill.ca.

658 ORCID

659 Nicholas DiStasio: 0000-0001-8846-6523

660 Maryam Tabrizian: 0000-0002-5050-4480

661 Notes

662 The authors declare no competing financial interest.

\section{$663 \square$ ACKNOWLEDGMENTS}

664 The authors graciously thank David Simon and Talin 665 Ebrahimian for help in planning experiments, Sylvain 666 Essiembre for GPC measurements, and Emily Buck for help 667 with manuscript editing. S.L. is financed by an operating grant 668 from the Canadian Institutes of Health Research, and M.T. is 669 funded by grants from both the Canadian Institutes for Health 670 Research and the National Sciences and Engineering Research 671 Council of Canada.

\section{REFERENCES}

673 (1) Green, J. J.; Langer, R.; Anderson, D. G. A Combinatorial 674 Polymer Library Approach Yields Insight Into Nonviral Gene 675 Delivery. Acc. Chem. Res. 2008, 41, 749-759.

676 (2) Bishop, C. J.; Kozielski, K. L.; Green, J. J. Exploring the Role of 677 Polymer Structure on Intracellular Nucleic Acid Delivery Via 678 Polymeric Nanoparticles. J. Controlled Release 2015, 219, 488-499.

679 (3) Sunshine, J. C.; Akanda, M. I.; Li, D.; Kozielski, K. L.; Green, J. J. 680 Effects of Base Polymer Hydrophobicity and End-Group Modification 681 on Polymeric Gene Delivery. Biomacromolecules 2011, 12, 35926823600 .

683 (4) Keeney, M.; Ong, S.-G.; Padilla, A.; Yao, Z.; Goodman, S.; Wu, J. 684 C.; Yang, F. Development of Poly(B-Amino Ester)-Based Biodegrad685 able Nanoparticles for Nonviral Delivery of Minicircle DNA. ACS 686 Nano 2013, 7, 7241-7250.

687 (5) Cheng, W.; Wu, D.; Liu, Y. Michael Addition Polymerization of 688 Trifunctional Amine and Acrylic Monomer: A Versatile Platform for 689 Development of Biomaterials. Biomacromolecules 2016, 17, 31156903126

691 (6) Zhou, D.; Gao, Y.; O'Keeffe Ahern, J.; A, S.; Xu, Q.; Huang, X.; 692 Greiser, U.; Wang, W. Development of Branched Poly(5-Amino-1693 Pentanol-Co-1,4-Butanediol Diacrylate) With High Gene Trans694 fection Potency Across Diverse Cell Types. ACS Appl. Mater. 695 Interfaces 2016, 8, 34218-34226.

696 (7) Shmueli, R. B.; Sunshine, J. C.; Xu, Z.; Duh, E. J.; Green, J. J. 697 Gene Delivery Nanoparticles Specific for Human Microvasculature 698 and Macrovasculature. Nanomedicine 2012, 8, 1200-1207.
(8) Cho, S.-W.; Yang, F.; Son, S. M.; Park, H.-J.; Green, J. J.; 699 Bogatyrev, S.; Mei, Y.; Park, S.; Langer, R.; Anderson, D. G. 700 Therapeutic Angiogenesis Using Genetically Engineered Human 701 Endothelial Cells. J. Controlled Release 2012, 160, 515-524. 702

(9) Green, J. J.; Zugates, G. T.; Tedford, N. C.; Huang, Y. H.; 703 Griffith, L. G.; Lauffenburger, D. A.; Sawicki, J. A.; Langer, R.; 704 Anderson, D. G. Combinatorial Modification of Degradable Polymers 705 Enables Transfection of Human Cells Comparable to Adenovirus. 706 Adv. Mater. 2007, 19, 2836-2842.

707

(10) Theoharis, S.; Manunta, M.; Tan, P. H. Gene Delivery to 708 Vascular Endothelium Using Chemical Vectors: Implications for 709 Cardiovascular Gene Therapy. Expert Opin. Biol. Ther. 2007, 7, 627- 710 643.

(11) Möckl, L.; Hirn, S.; Torrano, A. A.; Uhl, B.; Bräuchle, C.; 712 Krombach, F. The Glycocalyx Regulates the Uptake of Nanoparticles 713 by Human Endothelial Cells in Vitro. Nanomedicine (London, U. K.) 714 2017, 12, 207-217.

715

(12) Adamson, P. D.; Dweck, M. R.; Newby, D. E. The Vulnerable 716 Atherosclerotic Plaque: In Vivo Identification and Potential 717 Therapeutic Avenues. Heart 2015, 101, 1755-1766.

(13) Kheirolomoom, A.; Kim, C. W.; Seo, J. W.; Kumar, S.; Son, D. 719 J.; Gagnon, M. K. J.; Ingham, E. S.; Ferrara, K. W.; Jo, H. 720 Multifunctional Nanoparticles Facilitate Molecular Targeting and 721 miRNA Delivery to Inhibit Atherosclerosis in $\operatorname{ApoE}(-/-)$ Mice. ACS 722 Nano 2015, 9, 8885-8897.

(14) Chung, J.; Shim, H.; Kim, K.; Lee, D.; Kim, W. J.; Kang, D. H.; 72 Kang, S. W.; Jo, H.; Kwon, K. Discovery of Novel Peptides Targeting 725 Pro-Atherogenic Endothelium in Disturbed Flow Regions -Targeted 726 siRNA Delivery to Pro-Atherogenic Endothelium in Vivo. Sci. Rep. 727 2016, 6, 25636.

(15) Nahrendorf, M.; Jaffer, F. A.; Kelly, K. A.; Sosnovik, D. E. 729 Aikawa, E.; Libby, P.; Weissleder, R. Noninvasive Vascular Cell 730 Adhesion Molecule-1 Imaging Identifies Inflammatory Activation of 731 Cells in Atherosclerosis. Circulation 2006, 114, 1504-1511. 732

(16) Tabas, I.; García-Cardeña, G.; Owens, G. K. Recent Insights 733 Into the Cellular Biology of Atherosclerosis. J. Cell Biol. 2015, 209, 734 $13-22$.

(17) Collins, T.; Read, M. A.; Neish, A. S.; Whitley, M. Z.; Thanos, 736 D.; Maniatis, T. Transcriptional Regulation of Endothelial Cell 737 Adhesion Molecules: NF-Kappa B and Cytokine-Inducible Enhancers. 738 FASEB J. 1995, 9, 899-909.

(18) Gareus, R.; Kotsaki, E.; Xanthoulea, S.; Van Der Made, I.; 740 Gijbels, M. J. J.; Kardakaris, R.; Polykratis, A.; Kollias, G.; De Winther, 741 M. P. J.; Pasparakis, M. Endothelial Cell-Specific NF-Kappa B 742 Inhibition Protects Mice From Atherosclerosis. Cell Metab. 2008, 8, 743 372-383.

(19) Dagvadorj, J.; Naiki, Y.; Tumurkhuu, G.; Hassan, F.; Islam, S.; 745 Koide, N.; Mori, I.; Yoshida, T.; Yokochi, T. Interleukin-10 Inhibits 746 Tumor Necrosis Factor-Alpha Production in Lipopolysaccharide- 747 Stimulated RAW 264.7 Cells Through Reduced Myd88 Expression. 748 Innate Immun. 2008, 14, 109-115.

(20) Pinderski, L. J.; Fischbein, M. P.; Subbanagounder, G.; 750 Fishbein, M. C.; Kubo, N.; Cheroutre, H.; Curtiss, L. K.; Berliner, 751 J. A.; Boisvert, W. A. Overexpression of Interleukin-10 by Activated T 752 Lymphocytes Inhibits Atherosclerosis in LDL Receptor-Deficient 753 Mice by Altering Lymphocyte and Macrophage Phenotypes. Circ. Res. 754 2002, 90, 1064-1071.

(21) Liu, Y.; Li, D.; Chen, J.; Xie, J.; Bandyopadhyay, S.; Zhang, D.; 756 Nemarkommula, A. R.; Liu, H.; Mehta, J. L.; Hermonat, P. L. 757 Inhibition of Atherogenesis in LDLR Knockout Mice by Systemic 758 Delivery of Adeno-Associated Virus Type 2-hIL-10. Atherosclerosis 759 2006, 188, 19-27.

(22) Kamaly, N.; Fredman, G.; Fojas, J. J. R.; Subramanian, M.; 761 Choi, W. I.; Zepeda, K.; Vilos, C.; Yu, M.; Gadde, S.; Wu, J.; Milton, 762 J.; Carvalho Leitao, R.; Rosa Fernandes, L.; Hasan, M.; Gao, H.; 763 Nguyen, V.; Harris, J.; Tabas, I.; Farokhzad, O. C. Targeted 764 Interleukin-10 Nanotherapeutics Developed With a Microfluidic 765 Chip Enhance Resolution of Inflammation in Advanced Athero- 766 sclerosis. ACS Nano 2016, 10, 5280-5292. 
768 (23) Namiki, M.; Kawashima, S.; Yamashita, T.; Ozaki, M.; Sakoda, 769 T.; Inoue, N.; Hirata, K.-I.; Morishita, R.; Kaneda, Y.; Yokoyama, M. 770 Intramuscular Gene Transfer of Interleukin-10 cDNA Reduces 771 Atherosclerosis in Apolipoprotein E-Knockout Mice. Atherosclerosis 772 2004, 172, 21-29.

(24) Wang, P.; Wu, P.; Siegel, M. I.; Egan, R. W.; Billah, M. M. 774 Interleukin (IL)-10 Inhibits Nuclear Factor Kappa B (NF Kappa B) 775 Activation in Human Monocytes. IL-10 and IL-4 Suppress Cytokine 776 Synthesis by Different Mechanisms. J. Biol. Chem. 1995, 270, 95587779563.

778 (25) Han, X.; Kitamoto, S.; Lian, Q.; Boisvert, W. A. Interleukin-10 779 Facilitates Both Cholesterol Uptake and Efflux in Macrophages. J. 780 Biol. Chem. 2009, 284, 32950-32958.

781 (26) Niemand, C.; Nimmesgern, A.; Haan, S.; Fischer, P.; Schaper, 782 F.; Rossaint, R.; Heinrich, P. C.; Müller-Newen, G. Activation of 783 STAT3 by IL-6 and IL-10 in Primary Human Macrophages is 784 Differentially Modulated by Suppressor Of Cytokine Signaling 3. J. 785 Immunol. 2003, 170, 3263-3272.

786 (27) Riley, J. K.; Takeda, K.; Akira, S.; Schreiber, R. D. Interleukin78710 Receptor Signaling Through the JAK-STAT Pathway. Require788 ment for Two Distinct Receptor-Derived Signals for Anti-Inflamma789 tory Action. J. Biol. Chem. 1999, 274, 16513-16521.

790 (28) Qin, H.; Holdbrooks, A. T.; Liu, Y.; Reynolds, S. L.; 791 Yanagisawa, L. L.; Benveniste, E. N. SOCS3 Deficiency Promotes 792 M1Macrophage Polarization and Inflammation. J. Immunol. 2012, 793 189, 3439-3448.

794 (29) Pike, K. A.; Hutchins, A. P.; Vinette, V.; Théberge, J.-F.; 795 Sabbagh, L.; Tremblay, M. L.; Miranda-Saavedra, D. Protein Tyrosine 796 Phosphatase $1 \mathrm{~B}$ is a Regulator of the Interleukin-10-Induced 797 Transcriptional Program in Macrophages. Sci. Signaling 2014, 7, Ra43. 798 (30) Sunshine, J. C.; Peng, D. Y.; Green, J. J. Uptake and 799 Transfection With Polymeric Nanoparticles are Dependent on 800 Polymer End-Group Structure, but Largely Independent of Nano801 particle Physical and Chemical Properties. Mol. Pharmaceutics 2012, 9, $8023375-3383$.

803 (31) Zhou, D.; Cutlar, L.; Gao, Y.; Wang, W.; O’Keeffe-Ahern, J.; 804 Mcmahon, S.; Duarte, B.; Larcher, F.; Rodriguez, B. J.; Greiser, U.; 805 Wang, W. The Transition From Linear to Highly Branched Poly(B806 Amino Esters): Branching Matters for Gene Delivery. Sci. Adv. 2016, $8072,1600102$.

808 (32) Robins, R. S.; Lemarié, C. A.; Laurance, S.; Aghourian, M. N.; $809 \mathrm{Wu}$, J.; Blostein, M. D. Vascular Gas6 Contributes to Thrombogenesis 810 and Promotes Tissue Factor Up-Regulation After Vessel Injury in 811 Mice. Blood 2013, 121, 692-699.

812 (33) Kim, J.; Kang, Y.; Tzeng, S. Y.; Green, J. J. Synthesis and 813 Application of Poly(Ethylene Glycol)-Co-Poly(B-Amino Ester) 814 Copolymers for Small Cell Lung Cancer Gene Therapy. Acta 815 Biomater. 2016, 41, 293-301.

816 (34) Williams, L.; Bradley, L.; Smith, A.; Foxwell, B. Signal 817 Transducer And Activator Of Transcription 3 is the Dominant 818 Mediator of the Anti-Inflammatory Effects of IL-10 in Human 819 Macrophages. J. Immunol. 2004, 172, 567-576.

820 (35) Qin, H.; Wilson, C. A.; Roberts, K. L.; Baker, B. J.; Zhao, X.; 821 Benveniste, E. N. IL-10 Inhibits Lipopolysaccharide-Induced CD40 822 Gene Expression Through Induction of Suppressor Of Cytokine 823 Signaling-3. J. Immunol. 2006, 177, 7761-7771.

824 (36) Zhou, L.; Qu, X.; Guo, Y.; Wang, M.; Lei, B.; Ma, P. X. 825 Branched Glycerol-Based Copolymer With Ultrahigh P65 siRNA 826 Delivery Efficiency for Enhanced Cancer Therapy. ACS Appl. Mater. 827 Interfaces 2018, 10, 4471-4480.

828 (37) Zhou, D.; Gao, Y.; Aied, A.; Cutlar, L.; Igoucheva, O.; 829 Newland, B.; Alexeeve, V.; Greiser, U.; Uitto, J.; Wang, W. Highly 830 Branched Poly(B-Amino Esters) for Skin Gene Therapy. J. Controlled 831 Release 2016, 244, 336-346.

832 (38) Cutlar, L.; Zhou, D.; Gao, Y.; Zhao, T.; Greiser, U.; Wang, W.; 833 Wang, W. Highly Branched Poly(B-Amino Esters): Synthesis and 834 Application in Gene Delivery. Biomacromolecules 2015, 16, 26098352617
(39) Liu, S.; Gao, Y.; A, S.; Zhou, D.; Greiser, U.; Guo, T.; Guo, R.; 836 Wang, W. Biodegradable Highly Branched Poly(B-Amino Esters) for 837 Targeted Cancer Cell Gene Transfection. ACS Biomater. Sci. Eng. 838 2017, 3, 1283-1286.

(40) Huang, J.-Y.; Gao, Y.; Cutlar, L.; O’Keeffe-Ahern, J.; Zhao, T.; 840 Lin, F.-H.; Zhou, D.; Mcmahon, S.; Greiser, U.; Wang, W.; Wang, W. 841 Tailoring Highly Branched Poly(B-Amino Esters): A Synthetic 842 Platform for Epidermal Gene Therapy. Chem. Commun. (Cambridge, 843 U. K.) 2015, 51, 8473-8476.

844

(41) Gao, Y.; Huang, J.-Y.; O’Keeffe Ahern, J.; Cutlar, L.; Zhou, D.; 845 Lin, F.-H.; Wang, W. Highly Branched Poly(B-Amino Esters) for 846 Non-Viral Gene Delivery: High Transfection Efficiency and Low 847 Toxicity Achieved by Increasing Molecular Weight. Biomacromolecules 848 2016, 17, 3640-3647.

849

(42) Smith, T. T.; Stephan, S. B.; Moffett, H. F.; Mcknight, L. E.; Ji, 850 W.; Reiman, D.; Bonagofski, E.; Wohlfahrt, M. E.; Pillai, S. P. S.; 851 Stephan, M. T. In Situ Programming of Leukaemia-Specific T Cells 852 Using Synthetic DNA Nanocarriers. Nat. Nanotechnol. 2017, 12, 853 813-820.

854

(43) Park, H.-J.; Lee, J.; Kim, M.-J.; Kang, T. J.; Jeong, Y.; Um, S. H.; 855 Cho, S.-W. Sonic Hedgehog Intradermal Gene Therapy Using a 856 Biodegradable Poly(B-Amino Esters) Nanoparticle to Enhance 857 Wound Healing. Biomaterials 2012, 33, 9148-9156.

858

(44) Gu, J.; Wang, X.; Jiang, X.; Chen, Y.; Chen, L.; Fang, X.; Sha, X. 859 Self-Assembled Carboxymethyl Poly (L-Histidine) Coated Poly (B- 860 Amino Ester)/DNA Complexes for Gene Transfection. Biomaterials 861 2012, 33, 644-658.

(45) Chung, E. J.; Tirrell, M. Recent Advances in Targeted, Self- 863 Assembling Nanoparticles to Address Vascular Damage Due to 864 Atherosclerosis. Adv. Healthcare Mater. 2015, 4, 2408-2422.

(46) Kelley, W. J.; Safari, H.; Lopez-Cazares, G.; Eniola-Adefeso, O. 866 Vascular-Targeted Nanocarriers: Design Considerations and Strat- 867 egies for Successful Treatment of Atherosclerosis and Other Vascular 868 Diseases. Wiley Interdiscip Rev. Nanomed Nanobiotechnol 2016, 8, 869 909-926.

870

(47) Ma, S.; Tian, X. Y.; Zhang, Y.; Mu, C.; Shen, H.; Bismuth, J.; 871 Pownall, H. J.; Huang, Y.; Wong, W. T. E-Selectin-Targeting Delivery 872 of MicroRNAs by Microparticles Ameliorates Endothelial Inflamma- 873 tion and Atherosclerosis. Sci. Rep. 2016, 6, 22910.

(48) Mastorakos, P.; Da Silva, A. L.; Chisholm, J.; Song, E.; Choi, W. 875 K.; Boyle, M. P.; Morales, M. M.; Hanes, J.; Suk, J. S. Highly 876 Compacted Biodegradable DNA Nanoparticles Capable of Over- 877 coming the Mucus Barrier for Inhaled Lung Gene Therapy. Proc. Natl. 878 Acad. Sci. U. S. A. 2015, 112, 8720-8725.

(49) Zhou, J.; Liu, J.; Cheng, C. J.; Patel, T. R.; Weller, C. E.; 880 Piepmeier, J. M.; Jiang, Z.; Saltzman, W. M. Biodegradable 881 Poly(Amine-Co-Ester) Terpolymers for Targeted Gene Delivery. 882 Nat. Mater. 2012, 11, 82-90.

(50) Harris, T. J.; Green, J. J.; Fung, P. W.; Langer, R.; Anderson, D. 884 G.; Bhatia, S. N. Tissue-Specific Gene Delivery Via Nanoparticle 885 Coating. Biomaterials 2010, 31, 998-1006.

(51) Tzeng, S. Y.; Yang, P. H.; Grayson, W. L.; Green, J. J. Synthetic 887 Poly(Ester Amine) and Poly(Amido Amine) Nanoparticles for 888 Efficient DNA and Sirna Delivery to Human Endothelial Cells. Int. 889 J. Nanomed. 2011, 6, 3309-3322.

890

(52) Hovsepian, E.; Penas, F.; Siffo, S.; Mirkin, G. A.; Goren, N. B. 891 IL-10 Inhibits the NF-KB and ERK/MAPK-Mediated Production of 892 Pro-Inflammatory Mediators by Up-Regulation of SOCS-3 in 893 Trypanosoma Cruzi-Infected Cardiomyocytes. PLoS One 2013, 8, 894 79445.

(53) Sun, L.; Louie, M. C.; Vannella, K. M.; Wilke, C. A.; Levine, A. 896 M.; Moore, B. B.; Shanley, T. P. New Concepts of IL-10-Induced 897 Lung Fibrosis: Fibrocyte Recruitment and M2 Activation in a CCL2/ 898 CCR2 Axis. Am. J. Physiol. Lung Cell Mol. Physiol. 2011, 300, L341- 899 53.

(54) Han, X.; Boisvert, W. A. Interleukin-10 Protects Against 901 Atherosclerosis by Modulating Multiple Atherogenic Macrophage 902 Function. Thromb. Haemostasis 2015, 113, 505-512. 
904 (55) Mizuguchi, H.; Xu, Z.; Ishii-Watabe, A.; Uchida, E.; Hayakawa, 905 T. IRES-Dependent Second Gene Expression is Significantly Lower 906 Than Cap-Dependent First Gene Expression in a Bicistronic Vector. 907 Mol. Ther. 2000, 1, 376-382.

908 (56) Qasimi, P.; Ming-Lum, A.; Ghanipour, A.; Ong, C. J.; Cox, M. 909 E.; Ihle, J.; Cacalano, N.; Yoshimura, A.; Mui, A. L.-F. Divergent 910 Mechanisms Utilized by SOCS3 to Mediate Interleukin-10 Inhibition 911 of Tumor Necrosis Factor Alpha and Nitric Oxide Production by 912 Macrophages. J. Biol. Chem. 2006, 281, 6316-6324.

913 (57) Clarke, C. J.; Hales, A.; Hunt, A.; Foxwell, B. M. IL-10914 Mediated Suppression of TNF-Alpha Production is Independent of 915 Its Ability to Inhibit NF Kappa B Activity. Eur. J. Immunol. 1998, 28, 916 1719-1726.

917 (58) Nam, J.; Aguda, B. D.; Rath, B.; Agarwal, S. Biomechanical 918 Thresholds Regulate Inflammation Through the NF-Kappa B 919 Pathway: Experiments and Modeling. PLoS One 2009, 4, e5262.

920 (59) He, H.; Lancina, M. G.; Wang, J.; Korzun, W. J.; Yang, H.; 921 Ghosh, S. Bolstering Cholesteryl Ester Hydrolysis in Liver: A 922 Hepatocyte-Targeting Gene Delivery Strategy for Potential Allevia923 tion of Atherosclerosis. Biomaterials 2017, 130, 1-13. 